\title{
CAMINHOS HISTÓRICOS DA COEDUCAÇÃO: REFLEXÕES SOBRE MISTURAS E SEPARAÇÕES DURANTE O ISOLAMENTO
}

\author{
CAMINOS HISTÓRICOS DE COEDUCACIÓN: REFLEXIONES SOBRE MEZCLAS Y \\ SEPARACIONES DURANTE EL AISLAMIENTO
}

https://orcid.org/0000-0002-9805-1708 Daniela Auad A

${ }^{\text {A }}$ Universidade Federal de São Carlos (UFSCar), Sorocaba, SP, Brasil Universidade Federal de Juiz de Fora (UFJF), Juiz de Fora, MG, Brasil

Recebido em: 30 abr. 2021 | Aceito em: 20 ag. 2021 Correspondência: Daniela Auad (auad.daniela@gmail.com)

\begin{abstract}
Resumo
O artigo focaliza a questão da escola mista no Brasil da segunda metade do século XIX até o século XX. Mistura ou separação de meninas e meninos no ambiente escolar gerou - e ainda gera - debates entre diversos atores da cena educacional e variados setores da sociedade, que em diferentes momentos históricos se ocuparam - e ainda se ocupam - do que sempre esteve no interior das escolas: as relações de gênero. Variadas pesquisas, jornais pedagógicos, decretos da Coleção de Leis do Império, além de ofícios e correspondências entre professores, são fontes que retratam esta temática tanto histórica como atual e necessária. As pesquisas e documentos evidenciam a partir dos diferentes ideais de escolarização, modelos de sociedade em disputa.
\end{abstract}

Palavras-chave: relações de gênero; coeducação; escola mista; distanciamento social.

\section{Resumen}

Este artículo se centra en la problemática de la escuela mixta en Brasil desde la segunda mitad del siglo XIX hasta el siglo XX. La mezcla o separación de niñas y niños en el ámbito escolar generó -y aún genera- debates entre varios actores de la escena educativa y varios sectores de la sociedad, que en diferentes momentos históricos se preocuparon -y aún se preocupan- por lo que siempre ha estado dentro de las escuelas: las relaciones de género. Diversas investigaciones, periódicos pedagógicos, decretos de la Recopilación de Leyes del Imperio, además de cartas y correspondencias entre maestros, son fuentes que retratan este tema tan histórico como actual y necesario. Las investigaciones y los documentos muestran, a partir de los diferentes ideales de escolarización, modelos de sociedad en disputa.

Palabras clave: Relaciones de género; coeducación; escuela mixta; distancia social. 


\section{A Introdução de uma "Antiga Novidade"}

O estudo de práticas escolares e de debates acerca da defesa ou da interdição do diálogo que considere a categoria gênero nas escolas se assenta em uma questão central tão antiga quanto ainda não esgotada, a saber: embora as escolas brasileiras sejam mistas, não temos, em nosso país, coeducação (Daniela AUAD, 2004)i . Apesar de as escolas terem meninas e meninos em mistura nos seus ambientes, há de se considerar a distinção entre os termos escola mista e coeducação. Tal distinção objetiva afirmar que colocar meninas e meninos juntos na escola não é o suficiente para promover a consideração do diálogo sobre as relações de gênero, tanto em uma perspectiva de igual valorização do que seja considerado masculino e feminino, quanto no que tange ao dinâmico debate sobre as polarizações e desigualdades às quais esse modelo binário conduz dentro e fora da escola.

No escopo dessa necessária, colocada e recorrente discussão, já se tem acúmulo no campo da pesquisa educacional, de modo que a referida distinção entre os termos escola mista e coeducação não é nova, apesar da sinonímia ainda corroborar a equivocada percepção que, uma vez tendo sido alcançada a escola mista, já teria sido fornecida toda a contribuição, de maneira oficial e sistemática, para o término das desigualdades de gênero (AUAD, 2004). A escola mista é um dos importantes aspectos para a implementação da coeducação, mas não o bastante para dizimar as relações de gênero hierárquicas na escola. Para chegar a essa conclusão, foi necessária a apropriação do conceito de mixité em pesquisas do campo da Sociologia da Educação, nas quais se entrelaçam estudos feministas, a categoria gênero e a análise de relações sociais que se estabelecem na escola, na política, no mercado de trabalho (Claude ZAIDMAN $^{\mathrm{ii}}$, 1995, 1996, 1998, 2002; Sabine FORTINO ${ }^{\mathrm{iii}}$, 2000; AUAD, 2004).

Assim, em diálogo com ramos da Sociologia, na pesquisa educacional foi possível ressignificar e refundar o que é percebido como coeducação e notar que a escola mista não é o suficiente para alcançar uma educação que não reforce o binarismo de gênero, não aprofunde as desigualdades e não banalize a violência contra os femininos e contra quem, a despeito do seu sexo e com sua existência, ousa negar o ideal de masculinidade dominante. Deste modo, a escola mista se coloca como uma das medidas de uma política pública coeducativa, que precisa contar com outras diretrizes para ações cotidianas, as quais vão além da simples mistura de meninos e meninas nas salas de aula e nos pátios escolares. 
Em tempo que estamos ainda a diferenciar os termos até então sinônimos - graficamente o que seria escola mista $\neq$ coeducação - há de se recuperar que a escola mista que hoje nos parece insuficiente para que nossos ideais de sociedade sejam alcançados foi ela mesma uma conquista e resultante de acirradas disputas, as quais ficaram marcadas na História da Educação Brasileira. Recuperar esse debate importa não apenas por estarmos em prolongado momento em que assistimos acalorados debates sobre dialogar ou silenciar sobre gênero na escola, mas também e, sobretudo, porque no contexto de pandemia que atravessamos, quando da escrita do presente texto, crianças e adolescentes estão trancadas ${ }^{\mathrm{iv}}$ em casa, alguns sem acesso sequer à escolarização emergencial on-line, que vem sendo ofertada de modo instável pelos sistemas de ensino, durante a pandemia.

Justamente por estamos diante de distanciamentos e isolamentos, sem nem mesmo que levássemos a termo tudo o que as misturas cotidianas e presenciais poderiam nos dar em termos de riquezas, diversidades e democracia, importa recuperar um conjunto de saberes históricos que mesmo tomando por vezes escola mista e coeducação como termos sinônimos para realizar seus debates e defesas, informam sobre as construções ao longo dos tempos acerca da educação conjunta de meninos e meninas e, por conseguinte, acerca do debate público do que hoje conhecemos como relações de gênero e educação.

Importa também ressaltar que dialogar sobre gênero e educação não corresponde exclusivamente a pensar mulher e educação, ou especialmente focalizar meninos e meninas na escola, ou ainda refletir sobre homens e mulheres no mercado de trabalho, por exemplo. Apesar disso, não há debate de gênero e educação possível sem que sejam relembradas, tocadas e remexidas tais temáticas, uma vez que se trata de debate polifônico onde são escutadas vozes das militantes, das pesquisadoras e de toda gente que se ocupa de fazer encontrar, na academia, as melhores convicções presentes nos livros e nas ruas.

Destaque-se ainda que, no escopo da abordagem do presente texto, o debate de gênero independe do sexo dos sujeitos colocados na escola, na empresa, nas relações quaisquer que sejam elas. Estas, de todo modo, estarão eivadas pelas relações de poder pautadas nas categorias raça, classe, gênero, geração, orientação sexual e tantos outros marcadores de diferença que constituem as desigualdades e que, portanto, devem ser pensados também ao se elaborarem as soluções que rumem para a consideração das diversidades, das variadas identidades e da fluidez necessária às socializações plenas de liberdade.

Feitos os remarques acima, cumpre destacar que mistura e separação na escola, embora se trate de debate sub-representado no Brasil, sob a ótica apenas de artigos da grande imprensa 
ou de best-sellers que beiram a autoajuda ${ }^{\mathrm{v}}$, a mistura ou a separação de meninas e meninos no ambiente escolar foi questão candente em âmbito internacional, sendo que ressurge de tempos em tempos, com diferentes roupagens, tanto em território nacional quanto além-mar. Cumpre destacar que, no momento da escrita do presente texto, como dito, o mundo está em pandemia e, especialmente no Brasil, seguimos com necessidade de permanente distanciamento social e até isolamento doméstico, dada a escassez de leitos hospitalares, insuficiência de vacinas e excesso de negacionismo. Ao lado da conjuntura mundial em dificuldade em razão da pandemia, esta se encontra agravada especialmente no Brasil, pelo alastrar do vírus Sars-CoV2 no país e por um governo federal negacionista no que se refere ao que afirma a Ciência. Tal negacionismo se mostra desde a defesa de teorias terraplanistas, por ocupantes de Ministérios que negam que a Terra é redonda, até a negação do uso de máscaras no rosto e da eficácia das vacinas, como medidas básicas preconizadas para combate ao vírus que faz adoecer de Covid19 e seus desdobramentos junto à saúde das populações.

No momento da escrita deste texto, no Brasil, se sofre com altos índices de contaminação com a doença e com índices altíssimos de morte, sendo dizimadas também as populações indígenas e desmatada a floresta amazônica, em prol das benesses dadas, por parte do mesmo governo federal que nega a Ciência, aos madeireiros em criminosas atuações. É neste contexto, de mulher que escreve trancada e de crianças no interior dos lares tão diversos quanto sofridos pela fome e pelas múltiplas violências, que se colocam as reflexões sobre mistura e separações, durante o isolamento. Essas reflexões se operam como um modo de pensar a coeducação e, assim, fornecer dados históricos do caminho da escola mista que nos permitam acessar a coeducação que temos hoje, seja on-line, seja presencial, mas cada vez mais importante que seja, que ocorra, que se dê! Toda educação para a autonomia é melhor do que nenhuma educação, como pode nos conduzir a inspiração trazida por Paulo Freire ${ }^{\text {vi }}$ (1967) e por bell hooks ${ }^{\mathrm{vii}}$ (2018). Assim, diretamente da escrita com vista para a porta trancada, consigo pensar na história que nos deu a mistura da escola e que pode nos dar um futuro de encontros como prática de liberdade, sem separação, sem isolamento, com direitos à educação e à saúde assegurados.

Nessa perspectiva, no presente texto são marcantes as influências da conjuntura atual, ao se partir de conhecimento produzido em campo e em diálogo com referenciais teóricos legítimos, devidamente recuperado pelas lembranças trazidas à nossa revelia, durante os dias de isolamento que parecem não ter mais fim. Nesses tempos, tem se recuperado também o que foi dito de relevante sobre mistura, separação e coeducação, para, a partir desses diálogos 
históricos e de seus desdobramentos, pensar não apenas o distanciamento, mas também as escolarizações que se passam on-line e as escolarizações interrompidas, estas mal destinadas a uma maioria de pessoas sem acesso ao que se passa remotamente e, ainda, sem equipamentos como notebooks, computadores e celulares.

A introdução dessa "antiga novidade", que é pensar porque devemos misturar para melhor educar, nos revisita justamente no momento em que não podemos não apenas nos mesclar ou, como se diz usualmente, aglomerar. A despeito de imaginar que a pandemia pode nos tornar melhores ou piores, como também em conversas coloquiais tem se imaginado, há de se retomar como nos tornamos o que somos para tentar imaginar no que estamos nos tornando, nos assegurando de recuperar os caminhos já trilhados para evitar os retrocessos que nos espreitam, como o perigo na esquina, apesar de termos feito tudo que fizemos. No mínimo, há de se esperar que o distanciamento social somado ao cenário político governamental não serão elementos suficientes para acabar com os ideais pretendidos por quem historicamente defendeu a escola mista, por quem pensou, de modo militante e rigoroso, a coeducação, e por quem, com lógica e respeito à vida, acredita na vacina, na terra redonda e na democracia.

\section{A histórica trilha da coeducação, via defesa da escola mista}

Um conjunto de pesquisas científicas na área das Ciências Humanas, em especial no campo da educação, nos contam sobre como o Brasil enfrentou, como um dado da implantação de seus sistemas de ensino, a polêmica entre escola mista e educação separada. O tema expressa como a escolha entre escola mista e escola separada por sexo pode representar e revelar as dinâmicas de mudanças sociais e culturais mais amplas, e não apenas ligadas às relações de gênero.

Para debater e analisar o campo de pesquisa no início dos anos 2000, na cidade de São Paulo, Daniela Auad considera uma interessante variedade de fontes, na escrita da tese Relações de Gênero nas práticas escolares: da escola mista ao ideal de co-educação (2004). A autora utiliza jornais pedagógicos localizados na Biblioteca Nacional que trazem matérias com debates sobre a temática do ensino misto e as vantagens ou desvantagens desse modelo, além de ofícios e correspondência entre professores encontrados na Série Educação do Arquivo Nacional. Para debater o aspecto legal do tema, são trabalhados decretos presentes na Coleção de Leis do Império e relatórios dos Ministros do Império. O exame desses documentos evidencia, a partir de criteriosa pesquisa, posições opostas e em disputa em relação às estratégias e ao modelo 
mais adequado para formar meninos e meninas. Cumpre destacar que essa tensão não se encerrou após o estabelecimento das escolas mistas no Brasil, de modo a trazer periodicamente o debate do tema à cena educacional, seja em pesquisa, seja no âmbito do senso comum, até a atualidade.

Na tese citada, Auad apresenta os efeitos produzidos pela controvérsia escola mista versus educação separada de meninas e meninos em estudo comparado a partir de pesquisas coletadas sobre o tema em variados países da Europa, da América Latina e na América estadunidense. Para realizar o que se pode chamar de uma história da educação mista, a pesquisadora feminista realizada seleção bibliográfica na biblioteca do Instituto de Pesquisa sobre as Sociedades Contemporâneas (IRESCO, laboratório de pesquisa ligado ao Centro Nacional de Pesquisa Científica/CNRS, associado à Universidade Paris VIII, Saint-Denis, na França), no sistema DEDALUS (Sistema Integrado de Bibliotecas da USP) e na Biblioteca Ana Maria Poppovic (da Fundação Carlos Chagas).

Auad aliou o debate histórico sobre a escola mista à temática das relações de gênero na escola, de modo a fornecer elementos para a superação de assimetrias e diferenças hierarquizadas entre o masculino e o feminino, na esfera mais ampla, tanto da historiografia da educação quanto das políticas públicas. Os dados sobre esse estudo comparado não serão tematizados no presente artigo, a bem do aprofundamento do caso brasileiro, aqui focalizado em especial. Assim, na perspectiva ainda da comparação, agora de diferentes momentos históricos brasileiros, há de se observar o que constatou a mesma pesquisadora quinze anos após as conclusões de sua tese, acima citada. Em companhia das pesquisadoras pernambucanas Janaína Guimarães ${ }^{\text {viii }}$ e Camila Roseno ${ }^{\text {ix }}$, em artigo sobre relações de gênero na Educação Básica, a autora analisa projetos de lei pretensamente proibitivos quanto ao diálogo sobre relações de gênero na escola, os quais colocam em disputa a partir de modelos de sociedade, via políticas públicas e práticas educacionais, no que se refere à autonomia e igualdade de direitos.

Ao partir do conceito de gênero de Joan W. Scott ${ }^{\mathrm{x}}$ (1995), da compreensão de política de Chantal Mouffe ${ }^{\mathrm{xi}}$ (2015) e da crítica feminista à produção do conhecimento, de Donna Haraway ${ }^{x i}$, as autoras (AUAD, GUIMARÃES e ROSENO, 2019) expressam como que setores ultraconservadores nos dias de hoje ainda clamam por uma educação que ensine a desigual separação de meninas e meninos. São grupos que colocam em disputa a defesa de um único modelo de família, com especial binarismo de gênero e que não deixa espaço para variadas manifestações identitárias tanto de masculinidades não hegemônicas quanto de mulheridades 
diversas, assim como de sujeitos que afirmam suas existências sem se enquadrarem nas polarizações entre o que se percebe como homem e o que se percebe como mulher.

Seja em pesquisa do início dos anos 2000, seja em pesquisa no corrente ano, parece perene o tensionamento entre separação e mistura de meninas e meninos, em nome de diferentes ideais de sociedade, a partir do ordenamento escolar. Como será possível notar a seguir, as disputas que hoje podem muitas vezes ser vistas como novidades, fazem parte da constituição dos sistemas escolares em nosso país, ainda que aparentem ineditismo a cada vez que ressoam seus ecos conservadores, nos diferentes tempos e espaços sociais.

Hyrla Leal ${ }^{x i i i}$ expressa com bastante clareza as dinâmicas para as quais o olhar deste artigo se volta. A autora investigou a concepção da educação feminina da década de 20 , sob a ótica dos intelectuais proeminentes da época. Por meio dessa investigação, ela buscou, na fala dos educadores chamados "renovadores" ou "progressistas", defensores da coeducação, elementos reveladores de uma mudança, naquele momento, na concepção e na instrução da mulher. A autora constatou, no entanto, que, apesar de se intitularem "paladinos da modernidade", esses educadores resistiram em conceder espaço às mulheres, reinvestindo-as da tradicional missão de "guardiãs do lar" e só admitindo a sua participação no magistério primário. Ao longo do estudo, Leal traça imprescindível quadro para o entendimento da inserção da escola mista no Brasil, por ela denominada "co-educação", de modo sinônimo neste caso, portanto.

A autora também destaca que, na Colônia ${ }^{\text {xiv }}$, as mulheres viviam reclusas, e, geralmente, em estado de "indigência cultural", segundo alguns estudiosos do período. Havia um temor generalizado, na sociedade da época, quanto ao aprendizado da leitura e escrita pelas meninas. A instrução das moças poderia resultar, segundo os pais, em bilhetes de namorados e na leitura de livros considerados proibidos para as mulheres. Os conventos femininos eram uma exceção. Neles, as mulheres recebiam rudimentos de leitura, escrita, música e trabalhos domésticos. As primeiras experiências, nesses conventos femininos, datam, segundo Leal, dos séculos XVI e XVII, com a criação, por religiosas, dos chamados "recolhimentos". Esses estabelecimentos religiosos para mulheres multiplicaram-se e foram três os principais recolhimentos do período colonial: Desterro, na Bahia; Ajuda, no Rio de Janeiro; e Santa Tereza, em São Paulo (LEAL, 1997, p. 71-72).

No século XIX, com as reformas joaninas, as mulheres tiveram raras oportunidades educacionais laicas. As mulheres de classe superior continuavam com as preceptoras estrangeiras e, somente no Império, abriram-se mais escolas para meninas. Estas, no entanto, 
eram pouco frequentadas e, como denuncia Leal, não havia professoras suficientes (LEAL, 1997, p. 76). O preconceito ainda era muito forte em relação à instrução feminina. A Lei Imperial de 1827 autorizou a abertura de classes femininas e introduziu algumas diferenças entre os currículos dos meninos e o das meninas, em função do que se esperava socialmente dos diferentes sexos. Segundo esse decreto, determinadas disciplinas, como, por exemplo, a geometria, de nada serviria às meninas. Pela posição da mulher no meio social, a sua instrução era preterida em favor da preparação para o casamento.

Em 9 de junho de 1827, surgiu, no Parlamento, a proposta de criação de escolas públicas de primeiras letras. Segundo um de seus autores, Ferreira França, o magistério “das primeiras letras" seria exercido prioritariamente pelas mulheres, enquanto os níveis mais elevados (liceus, ginásios e academias) continuariam nas mãos de professores homens. Leal constata, diante dessa diferenciação hierarquizada, que, em função da exigência das camadas mais altas da sociedade, os estudos mais avançados eram os mais valorizados, assim como seus professores. Deste modo, a feminização do magistério primário, identificado como "sacerdócio" e como prolongamento das funções maternais, acabou revertendo em prejuízo para a sua profissionalização, acentuando cada vez mais a deficiência da formação das professoras. Não seria necessário qualificar, com vistas à profissionalização, trabalhadoras que já possuíam, de modo instintivo, as atribuições necessárias para o desempenho da função. O desprestígio do magistério relaciona-se, assim, com o fato de a Escola Normal representar apenas uma instituição de cultura geral, com leve coloração profissionalizante, como acentua Hyrla Leal.

Vale notar, ao mencionar as Escolas Normais e a desqualificação por elas sofridas, a chamada Escola Normal "da Praça". Essa era a designação pela qual o Colégio Caetano de Campos, situado à Praça da República, na cidade de São Paulo, era conhecido. Tal Escola Normal foi criada em 1846. Era destinada somente aos homens da província, pois somente estes poderiam ensinar meninos. Ficou inativa por um determinado período, a partir de 1867 , e se reinstalou somente em 1876. Foi aberta ao público feminino quando foi reinstalada. A grande demanda feminina que suscitou exigiu, por falta de espaço, a coeducação, que seria abolida em 1890, graças às inúmeras pressões, tanto de professores quanto de diretores das escolas.

No final do Império, os currículos das escolas femininas ainda eram dedicados à preparação para o trabalho doméstico, pois, esses currículos eram compostos de atividades como corte e costura, bordados, desenho e música. Com isso, pouco espaço era reservado à instrução considerada de cunho erudito e intelectual. Observa-se, no entanto, que essa orientação não era seguida pelas escolas metodistas do mesmo período. 
Uma das primeiras experiências de escola mista data de 1870, quando da fundação da Escola Americana, a qual, mais tarde, foi denominada Mackenzie. Esta serviu de padrão para as reformas do ensino público de São Paulo. Na referida escola, estavam presentes métodos pedagógicos considerados novos, como ensino graduado em séries, coeducação e um jardim da infância. Assim como o Colégio Piracicabano - fundado em 1881, a princípio só para moças, e depois aberto à coeducação — e o Colégio Granbery, em Juiz do Fora (MG), a Escola Americana recebia verbas do movimento das senhoras norte-americanas. Tratava-se de movimento interessado na formação das mulheres com forte preocupação religiosa subjacente. De todo modo, era uma postura diferente da dos brasileiros em relação à formação feminina. $\mathrm{O}$ currículo era variado e bem mais extenso, e revelava uma preocupação especial em relação à formação dos professores. Na maioria delas, a direção e orientação era atribuída a mulheres, como, por exemplo, Miss Martha Watts, que fundou o Colégio Piracicabano, e Miss Baxter, que dirigia o Internato Feminino (LEAL, 1997, p. 77).

As primeiras décadas do Período Republicano, iniciado em 1889, foram decisivas para a construção de um ideal de autonomia feminina. Foi nesse período que a imprensa feminina ganhou impulso e o ideal de liberação feminina sensibilizou diferentes setores sociais (LEAL, 1997, p. 78). Contudo, o projeto republicano tentou conciliar as novas oportunidades urbanas para a mulher com valores tradicionais. Assim, apesar das formas de socialização da mulher se diversificarem, não se pode debitar ao período grandes alterações no âmbito legal e político. O novo regime não representou às mulheres a conquista do direito de voto. Este foi obtido, em nosso país, pelo Código Eleitoral, em 1932 e, na Constituição Federal, apenas em 1934. Embora a instrução de meninas e mulheres ainda fosse precária nas escolas públicas, nas particulares, com a República, a educação teve progressos visíveis. A laicização imposta pelo novo regime político foi fator importante para liberar, ao menos oficialmente, homens e mulheres, meninos e meninas, da tutela católica.

Com a República, estava formada a conjuntura ideal para o Brasil acompanhar a tendência de uma educação voltada para a civilização de base científica, com ideal reformador, consubstanciada no "escolanovismo". Os escolanovistas sintetizaram as suas reivindicações na defesa dos princípios democráticos e do ensino oficial, obrigatório, gratuito, leigo e misto. Como destaca Cecília Hanna Mate ${ }^{\mathrm{xv}}$, os projetos pedagógicos escolanovistas tinham as seguintes ideias-base: 1) A Nação como elemento unificador das diferenças; 2) A Modernidade como fonte de superação do que se considerava, à época, atrasos e percalços ao progresso; 3 ) A higienização e a regeneração física, moral e social como elemento de ordenação e controle 
necessário para uma desejada disciplina social, harmônica e laboriosa; e 4) A organização da cultura como meio de homogeneização das tradições e modos de ser sociais (MATE, 1991, p. $10)$.

O lema do movimento da Escola Nova era a "educação para uma civilização em mudança, ou a reforma da sociedade pela reforma da educação" (LEAL, 1997, p. 102). Assim, como aponta Leal (1997), John Dewey, filósofo americano que viveu na virada do século XIX para o XX e influenciou educadores de várias partes do mundo, era a inspiração do movimento. No Brasil, sob a liderança de Anísio Teixeira, o movimento da Escola Nova fundou a percepção do pragmatismo e da democracia como importantes ingredientes da educação.

Os educadores que expressavam esse pensamento no Brasil e faziam parte do referido movimento eram chamados "pioneiros da nova educação" xvi . Eles emergiram como os paladinos da Modernidade, arautos da Razão e da Ciência, na busca de um "Novo Brasil", uma nação moderna e liberal em potência. A atuação dessa intelectualidade, no entanto, pode ser caracterizada por um descompasso entre o proclamado e o realizado, como atesta a contribuição da tese de doutorado de Hyrla Leal. Esta mostrou como os educadores adeptos da Escola Nova acreditavam, em teoria, na universalidade dos direitos humanos e, nesse âmbito, apregoavam a coeducação, sempre combatida pelos conservadores.

Em nome dos princípios igualitários, nomeavam mulheres para cargos públicos na educação. Contudo, na sua produção literária pedagógica e em alguns artigos publicados na grande imprensa, revelavam postura conservadora, tal como a vigente no conjunto da sociedade brasileira da época. Ao mesmo tempo em que incentivavam a coeducação e propiciavam a ocupação de postos por mulheres, mantinham a percepção de "proteção" das mulheres numa redoma de austeridade e bom comportamento, instigando-as a voltar para o lar.

Não havia, portanto, necessariamente uma preocupação em desobrigar meninas e mulheres de um currículo que as preparava para a vida no lar, de modo que necessidades práticas educacionais cotidianas se encontrassem com necessidades estratégicas condizentes com um ideal de igualdade de direitos, autonomia e liberdade. Além disso, também não havia o objetivo de se emanciparem as mulheres dos domínios masculinos. Na verdade, o que se notava predominantemente era uma forma "econômica" de organizar as classes escolares, de modo a afirmar a educação como direito de todos e a viabilizar a suposta "equalização de oportunidades", presentes no projeto liberal dos escolanovistas. Graças a essas contradições, Hyrla Leal lembra a existência de críticas que chegavam a afirmar que o escolanovismo não passou de um conjunto de "ideias fora do lugar", pautado por um autoritarismo oculto sob o 
rótulo do novo e do moderno, tornando público um "discurso científico sobre o povo e para o povo" (LEAL, 1997, p. 116).

Com avanços e retrocessos, sob aplausos e críticas, fato é que o Manifesto dos Pioneiros da Nova Educação apresentava, como indubitável mérito, a coeducação como um dos princípios importantes a serem discutidos. O documento afirma textualmente:

\begin{abstract}
"A escola unificada não permite ainda, entre os alunos de um e de outro sexo, outras separações que não sejam as que aconselham as suas aptidões psicológicas e profissionais, estabelecendo em todas as instituições 'a educação em comum' ou coeducação, que, pondo-os no mesmo pé de igualdade e envolvendo todo o processo educacional, torna mais econômica a organização da obra escolar e mais fácil sua graduação" (AZEVEDO, 1934, p. 67-68).
\end{abstract}

Apesar disso, Eustáquia Salvadora ${ }^{x v i i}$ de Sousa demonstra, ao focalizar as relações de gênero no ensino da Educação Física, como " ... a educação mista, em certos casos, pode contribuir para exacerbar as desigualdades das diferenças de gênero" (SOUSA, 1996, p. 94).

Ao remontar o caminho historicamente percorrido pelo seu objeto de estudo, Sousa destaca relevante dado sobre a implantação da escola mista, no Brasil:

\begin{abstract}
"...Ficou demonstrado que a escola vem mantendo a separação e a hierarquização entre homens e mulheres, através da utilização de diferentes mecanismos, mesmo após a criação da escola mista. (...) Desta maneira, a escola primária mista, oficializada nos anos 20, sob inspiração do modelo liberal de educação - Escola Nova - buscou assegurar a construção social do masculino e do feminino, até então existente, através de conteúdos de ensino, das normas, dos objetos, do espaço físico, das técnicas e, especialmente, técnicas do corpo - suas maneiras de pensar, sentir e agir. Assim, o programa de Educação Física determinava que a ginástica rítmica e 'a interpretação, por meio de gestos e atitudes, da emoção provocada pela música' fossem atividades exclusivas das meninas, enquanto as evoluções militares e exercícios de braço seriam executados apenas pelos meninos. Estava, pois, evidente que a co-educação na escola primária não alterara as simbologias da mulher - como um ser dotado de fragilidade e emoções - e do homem - como um ser dotado de força e razão - qualidades essas que, quando da implantação dos exercícios físicos na escola primária mineira, estabeleciam que, enquanto os meninos marchassem ao sol, as meninas executariam suaves movimentos, à sombra." (SOUSA, 1996, p. 87).
\end{abstract}

No contexto da escola mista dos anos 20, o que Eustáquia Salvadora de Sousa denomina como "esporte moderno" passou a ser mais um elemento de diferenciação desigual entre os sexos, no interior da disciplina de Educação Física. Com as normas, valores e gestos próprios dos jogos, as mulheres aparentavam um corpo frágil e elas se mantinham como "perdedoras". E sobre a "educação dos gestos", realizada no âmbito da escola mista, Sousa assinala:

\footnotetext{
" Ao longo da história, a manutenção dessas imagens de homem e de mulher, aliada à visão dicotômica - corpo/intelecto - exigiu que a escola mista continuasse diferenciando a educação por sexo. Cabia à Educação Física e aos Trabalhos Manuais educar os gestos 'masculinos e femininos', o que impedia a organização de turmas mistas nessas disciplinas e demandava a orientação de um professor e de uma professora." (SOUSA, 1996, p. 88).
} 
Com uma diferença de 16 anos em relação aos achados de Eustáquia Salvadora de

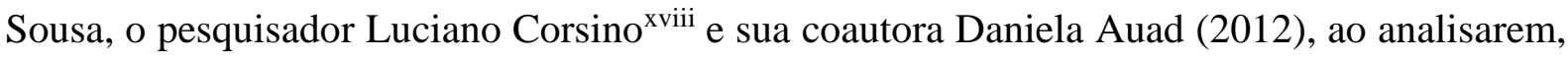
na periferia de São Paulo, de 2008 a 2010, as relações de gênero nas aulas de educação física escolar, foi possível constatar que tanto nas aulas de Educação Física quanto em parte da produção de conhecimento desse campo, diversas formas de resistência às hierarquizações de gênero e de saberes podem ser percebidas. Por um lado, meninas e mulheres e, por outro lado, pesquisadoras e pesquisadores lutam para ter práticas escolares e produzir conhecimentos que não reforcem polaridades, binarismos e desigualdades. Por outro lado, ao analisarem as relações de gênero, em observação de inspiração etnográfica das aulas de educação física, Corsino e Auad encontram disputas e resistência acerca de padrões restritos, essencialistas e determinados no que se refere ao masculino e ao feminino.

Diante de diálogo entre bibliografia selecionada e dados coletados no campo, a pesquisa com foco na educação física escolar - usual palco de debates sobre misturas e separações entre meninos e meninas, incluindo argumentos fisiológicos e biologizantes - constatou disputas de concepções e conflitos sobre quem pode jogar futebol, assim como sobre quem pode conhecer legitimamente o que pode ou não ocorrer entre jogos mistos nas aulas de educação física escolar. Ainda paira debate acirrado sobre quem pode estar nas quadras e quem pode ser voz dos discursos aceitos e mais prestigiosos acerca do que ocorre nas aulas.

Debater tais resistências e lutas no campo, nas salas de aula e nas quadras, em variados tempos e espaços, assim como apostar nas descontinuidades da lógica que se espera dominante, impõe pensar sobre hierarquizações e a coeducação como ferramenta para resistir em tempos de tensionamento de retrocesso, seja como se deu quando da implantação dos sistemas de ensino no Brasil, seja como hoje deve estar de dando, seja no ensino presencial, seja no ensino remoto emergencial, ainda a ser desvendado em seus meandros de misturas e separações também no distanciamento social e nos isolamentos impostos por variadas razões.

\section{Juntos, Separados, Misturados ou Isolados?}

Amparo Blat Gimeno ${ }^{\mathrm{xix}}$, ao analisar o histórico de sistemas de ensino latino-americanos, aponta como a "escola mista tem sido insuficiente para combater a discriminação das mulheres e, ainda, tem promovido apenas uma igualdade formal promotora de sutil e mascarada discriminação". Por essa razão, a autora defende que é necessário "ir mais além da escola mista e dar um passo adiante na direção da co-educação" (GIMENO, 1994, p. 127). 
Assim como assinala em 2004 Daniela Auad, a partir de contexto brasileiro, Gimeno, uma década antes, em 1994, adota o termo coeducação com um significado mais amplo do que a escolarização conjunta de alunos e alunas, ou seja, a escola mista. Segundo Gimeno, esta nova proposta partiria de um conceito integral de pessoa como ser autônomo e proporia uma variedade de modelos que permitissem a cada menina e a cada menino desenvolver sua personalidade de acordo com suas capacidades e aptidões. Para Gimeno, a formação da personalidade independeria das limitações e prescrições que as relações de gênero em nossa sociedade impõem a eles e a elas.

Às afirmações de Gimeno faz-se necessário acrescentar, sem que a autora tenha exatamente proposto tal desdobramento, que há de se rever, reconstruir e tecer dinamicamente até mesmo a percepção polarizada entre o que se entende por eles e elas, ou o conteúdo que cabe social e historicamente no que se entende por eles ou por elas, por meninas, meninos, homens, mulheres e demais categorias que se, por um lado, se colocam necessárias para a construção das políticas afirmativas, as quais demandam reconhecimento identitário, a fim de empreender necessárias acolhidas e reparações, por outro lado, podem reduzir subjetividades, desidratar experiências, simplificar trajetórias e empobrecer itinerários.

Quem se busca educar em cada modelo e, sobretudo, quais ideias de sociedade se pretende tecer com tais modelos? Como reinaugurar valores e questionar os ideários de cada época e de variados grupos em disputa também na atualidade, para manter em diálogo a educação, sem que o ensino prescreva o que é ser menina, o que é ser menino e por que essa conversa tem se dado apenas entre esses dois polos, afinal? Como os debates sobre escola mista e escola separada, sempre e em espiral revisitados, ainda que com diferentes roupagens, vão reaparecer - ou já estão reaparecendo - nos cenários que se desdobram com a pandemia, que se coloca sobre nós quando da escrita do presente texto? Quais impactos e efeitos podem ter, para o debate sobre relações de gênero na escola, o distanciamento social, o ensino remoto, o ensino híbrido e os variados isolamentos, perdas e lutos?

O presente texto pretendeu retomar o conteúdo sobre a História da Educação Brasileira e as relações de gênero, a fim de conhecermos parte do terreno sobre o qual se fundam nossas preocupações usuais e também aquelas que ainda não conhecemos, mas que sabemos que irão se avizinhar, desde que haja vida e possamos vicejar. 


\section{Referências}

AUAD, Daniela. Relações de Gênero nas práticas escolares: da escola mista ao ideal de coeducação. Tese de Doutorado. Faculdade de Educação da Universidade de São Paulo (FEUSP), 2004.

AUAD, Daniela; GUIMARÃES, Janaína; Roseno, Camila P. Gênero na Educação Básica Brasileira: a inconstitucionalidade de projetos proibitivos. ETD - Educação Temática Digital, Unicamp, Campinas, v.21, n.3, p.568-586, jul./set. 2019.

Educação para Democracia e Co-educação: apontamentos a partir da categoria gênero. Revista USP, número 56, Universidade de São Paulo, dezembro/janeiro/fevereiro 2002-2003. São Paulo, 2003.

AZEVEDO, Fernando de. Novos Caminhos e Novos Fins: a nova política de educação do Brasil. São Paulo, Companhia Editora Nacional, 1934.

BIDDULPH, Steve. Criando Meninos. São Paulo, Fundamento, 2003.

CORSINO, Luciano Nascimento; AUAD, Daniela. O professor diante das relações de gênero na educação física escolar. São Paulo: Cortez, 2012.

FORTINO, Sabine. Mixitè. In: HIRATA, Helena Sumiko; LABORIE, Françoise; LE DOARÉ, Hélène; SENOTIER, Danièle. (coordenation). Dictionnaire Critique du Féminisme. Paris, Presse Universitaire de France, 2000.

FREIRE, Paulo. Educação como prática da liberdade. Rio de Janeiro, Editora Paz e Terra LTDA, v. 199, 1967.

GIMENO, Amparo Blat. Informe sobre la igualdad de oportunidades educativas entre los sexos. Revista Iberoamericana de Educación, nº 6, p. 123-145, sept./dic. 1994.

HARAWAY, Donna. Saberes localizados: a questão da ciência para o feminismo e o privilégio da perspectiva parcial. Cadernos Pagu, v. 5, p. 07-41, 1995. Disponível em: <www.clam.org.br/bibliotecadigital/uploads/publicacoes/1065_926_hARAWAY.pdf>.

Acesso em: 12 jun. 2016.

HOOKS, bell. Ensinando a transgredir: a educação como prática de liberdade. WMF, São Paulo, 2018.

LEAL, Hyrla Aparecida Tucci. Amélias de Ontem: a educação feminina na concepção de intelectuais da década de vinte. Doutorado em História e Filosofia da Educação, São Paulo, Pontifícia Universidade Católica de São Paulo, 1997.

MATE, Cecília Hanna. Dimensões de Educação Paulista nos Anos 20: inquirindo, reformando, legitimando uma nova escola. São Paulo, Pontifícia Universidade Católica de São Paulo, Mestrado em História e Filosofia da Educação, 1991. 
MOUFFE, Chantal. Sobre o político. São Paulo: WMF Martins Fontes, 2015.

PREUSCHOFF, Gisela. Criando Meninas. São Paulo, Fundamento, 2003.

SCOTT, Joan W.Gênero: uma categoria útil de análise histórica. Educação e Realidade. Porto Alegre, v.20, n. ${ }^{\circ}$ 2, p. 71-99, 1995.

SOUSA, Eustáquia Salvadora de. Relações de gênero no ensino da educação física. Caderno Espaço Feminino, n. ${ }^{\circ}$ 3, p. 79-96, 1996.

ZAIDMAN, Claude. La mixité à l'école primaire. Paris, L'Harmattan, 1996.

La mixité, objet d'étude scientifique ou enjeu politique. Cahiers $d u$ GEDISST, Paris, IRESCO, CNRS, nº 14, 1995.

Mixité et Démocratie. In: MARIE-FRANCE e VALARIÉ-BOY (org.).

Faites de Femmes: processus identificatoires et contextes sociaux. França, Éditions les Pluriels de Psyché, 1998.

La mixité en questions: des résistances religieuses à la critique féministe, ou l'actualité de la question de la mixité scolaire. Raison Présente. Paris, Nouvelles Éditions Rationalistes, $\mathrm{n}^{\circ}$ 140, 2002.

\footnotetext{
${ }^{i}$ No presente texto, a cada primeira vez que se fizer referência a uma obra, será utilizado também o primeiro nome da(s) pessoa(s) que a escreveu, a bem da visibilidade de sujeitos que constroem o conhecimento. Também a bem da visibilidade das pesquisadoras, será, em nota, a cada primeira aparição textual, fornecido breve apresentação da autora. Daniela Auad é pedagoga, mestra e doutora em Educação, tendo concluído essas três formações na Faculdade de Educação da Universidade de São Paulo. No momento da escrita do presente texto, a pesquisadora e feminista é Docente permanente dos Programas de Pós-graduação em Educação da UFSCar-So e da UFJF, Universidades Federais localizadas respectivamente em São Paulo e em Minas Gerais.

ii Claude Zaidman foi Professora, Pesquisadora e Maître de Conférences em Sociologia da Universidade de Paris VII.

iii Sabine Fortino é Socióloga e Professora na Universidade de Paris X.

iv No presente texto as palavras serão ora grafadas no feminino, ora no masculino e feminino, ora de modo percebido como neutro, posto que o masculino genérico não se coaduna com a abordagem teórica assumida. $\mathrm{O}$ feminino genérico, por outro lado, poderá ser utilizado, como no caso da palavra a qual está relacionada a presente nota. Trata-se do uso do feminino genérico como recurso linguístico de reparação histórica, em razão da longeva e profunda invisibilidade das mulheres nos mais variados tempos e espaços, incluindo os conhecimentos produzidos em áreas majoritariamente femininas, como a área de educação.

v A exemplo dos livros que foram best-sellers, à época de seus lançamentos, Criando Meninos, de Steve Biddulph e Criando Meninas, de Gisela Preuschoff, ambos lançados em 2003. Trata-se de abordagens separatistas, baseadas na existência de uma essência tipicamente masculina oposta e complementar a uma essência tipicamente feminina. ${ }^{v i}$ Paulo Freire foi um educador brasileiro, pernambucano, cuja obra e importância histórica e atual não cabem na dimensão da presente nota, na qual apenas se indica a leitura de todos os seus livros e a tomada de inspiração em toda a sua abordagem educacional.

vii Segundo a autora, a letra minúscula usada para a escrita de seu nome pretende dar enfoque ao conteúdo de seu texto, e não à sua pessoa.

viii Doutora em História pela Universidade Federal de Pernambuco (UFPE), em Recife, e professora adjunta da Universidade de Pernambuco (UPE), em Petrolina.

ix Cofundadora da Biblioteca Feminista Virtual Nuvem Sapatão e do Sebo Cooperativo Sebo nas Canelas, Camila Roseno é mestra em Educação, pela Universidade de Pernambuco (UPE), em Petrolina, e doutoranda em Educação pela Universidade Federal de Juiz de Fora (UFJF), em Minas Gerais.

x Joan Wallach Scott é uma historiadora norte-americana cujo trabalho, inicialmente dedicado à história francesa (movimento operário e história intelectual) foi direcionado, na década de 1980, para a história das mulheres, a
} 
partir da perspectiva da categoria gênero. Joan Scott atualmente ocupa a cadeira Harold F. Linder no Instituto de Estudos Avançados de Princeton.

${ }^{\text {xi }}$ Chantal Mouffe é uma cientista política pós-marxista belga que desenvolve trabalhos na área da teoria política. Foi professora convidada em Harvard, Cornell, Princeton e no Centre National de la Recherche Scientifique. De 1989 a 1995, foi diretora de departamento no Collège International de Philosophie, em Paris. Atualmente, é Professora de Teoria Política na Universidade de Westminster, no Reino Unido.

xii Donna Haraway é uma bióloga, filósofa, escritora e professora emérita estadunidense, do Departamento de História da Consciência, na Universidade da Califórnia em Santa Cruz. É autora de diversos livros e artigos cuja temática se volta para Feminismo, Ciência e Produção de Conhecimento.

xiii Hyrla A. T. Leal é Professora Doutora da Pontifícia Universidade Católica de São Paulo (PUC/SP). Ela é autora da tese Amélias de Ontem: a educação feminina na concepção de intelectuais da década de vinte.

xiv O Período Colonial teve início no dito "Descobrimento", em 1500, e se estendeu até 1822, quando do "rompimento" com Portugal e instalação do Império.

xv Cecília Hanna Mate é Professora Doutora do Departamento de Metodologia e Prática de Ensino da Faculdade de Educação da Universidade de São Paulo (EDM/FEUSP).

xvi Dentre os mais conhecidos que assinaram o Manifesto dos Pioneiros da Nova Educação estão Anísio Teixeira, Fernando de Azevedo, Lourenço Filho, Carneiro Leão, Sampaio Dória, Almeida Jr., Afrânio Peixoto, Roquette Pinto, Caetano de Campos e as três mulheres, Noemy M. da Silveira, Armanda A. Alvaro e Cecília Meirelles.

xvii A autora é Professora Doutora da Faculdade de Educação da Universidade Federal de Minas Gerais.

xviii Pesquisador de origem paulista, com formação na Unifesp, no Mestrado, e na Unicamp, no Doutorado, Luciano Corsino atualmente é docente no Instituto Federal do Rio Grande do Sul (IFRGS), no Campus Rolante, onde também ocupa o cargo de Diretor de Ações Afirmativas.

xix Responsável pelos Programas da área de Educação do Instituto Valência da Mulher e Diretora do Programa de Formação do Professorado na Comunidade Valenciana, na Espanha. 